\title{
OPTIMASI PEMAKAIAN MATERIAL STRUKTUR DENGAN OPTIMASI BENTUK (SHAPE OPTIMIZATION) DAN CROSS SECTION PADA STRUKTUR RANGKA BATANG TERHADAP KENDALA RELIABILITAS MATERIAL MENGGUNAKAN METODE ALGORITMA GENETIK
}

\author{
Augusta Adha, Program Studi Teknik Sipil, Fakultas Teknik,Universitas Islam Riau \\ augusta.adha@eng.uir.ac.id
}

\begin{abstract}
Abstrak
Dewasa ini, proses kegiatan konstruksi dituntut mampu menerapkan prinsip-prinsip yang ramah lingkungan. Kegiatan konstruksi yang dimulai dari proses pengambilan material seperti semen, baja atau kayu sering kali dituding memberikan dampak kerusakan lingkungan yang sangat tinggi. Ditambah lagi dengan penggunaan material struktur yang sangat boros dengan dalih untuk membuat struktur aman menyebabkan jejak lingkungan yang ditinggalkan oleh kegiatan konstruksi menjadi semakin besar dan kentara.

Namun demikian, seiring perkembangan teknologi material dan metode konstruksi, saat ini kegiatan dan hasil konstruksi yang efisien dan ramah lingkungan telah menjadi hal yang wajib dan terus dikembangkan. Salah satu cara untuk efisiensi konstruksi adalah dengan optimasi struktur. Berbagai metode optimasi dikembangkan untuk menghasilkan struktur yang lebih efisien dan menggunakan material yang lebih sedikit, namun tetap mampu menahan beban-beban desain yang diberikan kepada struktur.
\end{abstract}

Salah satu metode struktur Meta-heuristic yang populer adalah metode algoritma genetik. Paper ini akan membandingkan metode optimasi struktur dengan modifikasi pada cross section dan modifikasi pada bentuk struktur (shape) dengan kombinasi cross section, untuk menahan beban struktur rencana dengan kendala-kendala tertentu. Sebuah struktur rangka batang sederhana menjadi subjek penelitian pada paper ini. Struktur rangka batang tersebut di optimasi dengan dua cara yaitu optimasi dengan perubahan cross section penampang dan optimasi dengan perubahan cross section penampang dan dilanjutkan dengan perubahan bentuk struktur.

Berdasarkan hasil analisa dapat di simpulkan, dengan menggunakan metode optimasi bentuk yang dikombinasikan dengan optimasi berat, maka didapat hasil optimasi struktur yang lebih baik.

Kata kunci:

Algoritma genetik, optimasi bentuk, reliabilitas 


\section{LATAR BELAKANG}

Ketergantungan manusia terhadap kegiatan konstruksi menyebabkan lebih setengah dari konsumsi energi tak terbarukan di gunakan pada sektor konstruksi. Atas alasan tersebut, industri konstruksi menjadi salah satu sektor dengan predikat tidak ramah lingkungan. Kebutuhan energi dan material untuk pemenuhan kegiatan konstruksi tersebut tumbuh secara eksponensial, sementara daya dukung lingkungan terhadap kebutuhan tersebut sangat terbatas.

Berdasarkan penelitian dari Willmot Dixon (Impact of Construction and the Building Environment, 2010) pada tahun 2010, estimasi pemakaian sumber daya lingkungan secara global untuk kebutuhan konstruksi dapat digambarkan pada tabel berikut:

Tabel 1. Estimasi pemakaian sumber daya lingkungan secara global untuk konstruksi

\begin{tabular}{|l|l|}
\hline \multicolumn{1}{|c|}{ Resource } & \multicolumn{1}{c|}{ (\%) } \\
\hline Energy & $45-50$ \\
\hline Water & 50 \\
\hline Materials for buildings and roads (by bulk) & 60 \\
\hline Agricultural land loss to buildings & 80 \\
\hline Timber products for construction & 60 (90\% of hardwoods) \\
\hline Coral reef destruction & 50 (indirect) \\
\hline Rainforest destruction & 25 (indirect) \\
\hline
\end{tabular}

Dari sisi teknologi struktur, kebutuhan material tidak lepas dari persyaratan kekuatan struktur. Struktur harus mampu menanggung beban-beban rencana sepanjang masa layannya. Kekuatan struktur tergantung pada kombinasi kekuatan serta konfigurasi dari elemen-elemen struktur. Seiring dengan paradigma baru konstruksi sipil yang lebih berwawasan lingkungan dan berkelanjutan, konstruksi bangunan diarahkan untuk menjadi lebih efisien dan ekonomis. Oleh karena itu, optimasi struktur yang tetap mengedepankan kehandalan struktur menjadi salah satu opsi yang populer.

Konsep kehandalan struktur tidak lepas dari adanya ketidakpastian dalam struktur yang meliputi ketidakpastian kekuatan material, geometri struktur, dan beban luar. Ketidakpastian suatu fungsi variable dalam struktur dihitung secara empiris melalui berbagai penelitian-penelitian dan uji coba. Berdasarkan data-data primer tersebut, fungsi variable dalam struktur disusun secara matematis

Konsep optimasi telah lama dikembangkan untuk menghemat pemakaian material struktur dengan tetap memenuhi fungsi kendala yang ditetapkan. Salah satu metode populer yang sering dipakai untuk melakukan optimasi struktur adalah metode algoritma genetik. Metode algoritma genetik mengambil filosofi evolusi organisme dalam menghadapi kendala. Proses evolusi yang terjadi pada organisme untuk mencapai level optimum meliputi kawin silang dan mutasi. Dengan proses evolusi tersebut, sebuah organisme optimum terhadap kendala dan memenuhi fungsi tujuan yang diinginkan akan terbentuk pada akhir proses evolusi.

\section{METODOLOGI}

II.1. Analisa Struktur Rangka Batang

Struktur rangka batang 2 dimensi memiliki DOF pada masing-masing elemen seperti gambar berikut:

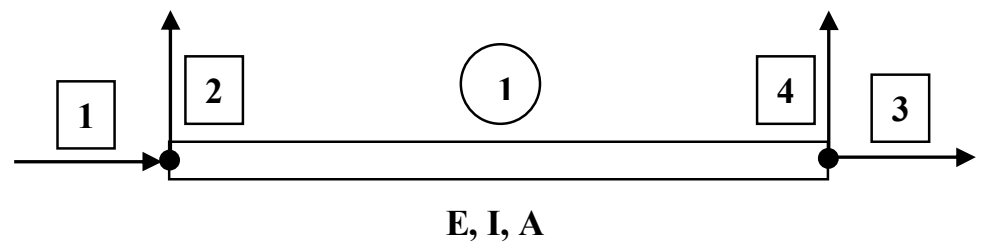

Gambar 1. Derajat kebebasan elemen struktur rangka batang 2D 
Matriks kekakuan yang membentuk elemen rangka batang dua dimensi adalah sebagai berikut:

$$
[k]_{e}=\left[\begin{array}{cccc}
E A / L & 0 & -E A / L & 0 \\
0 & 0 & 0 & 0 \\
-E A / L & 0 & E A / L & 0 \\
0 & 0 & 0 & 0
\end{array}\right]
$$

Dengan matriks transformasi koordinat sebagai berikut:

$$
[T]=\left[\begin{array}{cccc}
\cos \theta & \sin \theta & 0 & 0 \\
-\sin \theta & \cos \theta & 0 & 0 \\
0 & 0 & \cos \theta & \sin \theta \\
0 & 0 & -\sin \theta & \cos \theta
\end{array}\right]
$$

Dengan menggunakan persamaan berikut,

$$
[\mathrm{S}]_{\mathrm{mS}}=[\mathrm{T}]^{\mathrm{T}}[\mathrm{k}]_{\mathrm{e}}[\mathrm{T}]
$$

maka dapat dihitung matriks kekakuan elemen terhadap sumbu global yang dapat di rangkai menjadi matriks kekakuan struktur $[\mathrm{K}]$. Dengan menyelesaikan $\{\mathrm{X}\}$ pada persamaan berikut,$$
\{F\}=[K]\{X\}
$$

maka dapat di hitung deformasi struktur yang terjadi $\{X\}$ untuk mendapatkan gaya batang pada masingmasing elemen melalui persamaan,

$$
\{F E F\}=\{F\}+[k]_{e}\{\Delta\}
$$

\section{II.2. Kehandalan Struktur}

Beban rata-rata lebih kecil daripada beban nominal yang bekerja pada struktur. Pada kasus ini beban rata-rata adalah $80 \%$ dari beban nominal, sehingga dapat dirumuskan sebagai berikut :

$$
\mu_{L}=0.8 . L_{N}
$$

Perhitungan beban (load) rata-rata akibat beban nominal yang bekerja dapat digunakan Kriteria $\mathrm{X} \%$ Upper Tail.

$$
\ln L_{n}=\lambda_{L}+\left[\Phi^{-1}(X \%) \cdot \xi_{L}\right]
$$

Perhitungan tahanan (resistance) rata-rata akibat beban nominal yang bekerja dapat digunakan Kriteria $\mathrm{X} \%$ Lower Tail sebagai berikut :

$$
\ln R_{n}=\lambda_{R}+\left[\Phi^{-1}(X \%) \cdot \xi_{R}\right]
$$

Perhitungan nilai probabilitas keandalan elemen batang dilakukan dengan menggunakan persamaan berikut,

dimana,

$$
p_{F}=1-\Phi(\beta)
$$

$$
\beta=\frac{\lambda_{M}}{\xi_{M}}=\frac{\lambda_{R}-\lambda_{L}}{\sqrt{\xi_{R}^{2}+\xi_{L}^{2}}}
$$

\section{II.3. Metode Algoritma Genetik}

Metode algoritma genetik diusulkan pertama kali oleh John Holland. Prinsip dasar algoritma genetik meniru teori evolusi organisme dimana organisme yang memiliki fitness terbaik akan survive dan organisme yang tidak fit tidak akan dapat melanjutkan keturunannya. Fitness yang tinggi akan memberikan kesempatan lebih untuk individu bersangkutan melanjutkan keturunannya dan menurunkan sifat-sifat genetiknya. Individu - individu yang terlibat dalam proses tersebut merupakan solusi dari tujuan yang akan dicapai. Dengan prinsip ini, pada akhir fase optimasi, fitness dari individu akan mencapai tingkat terbaik yang memperlihatkan solusi terbaik dari fungsi tujuan.

Sebelum algoritma genetik di lakukan, sebuah metode untuk merepresentasikan sifat-sifat genetik dari sebuah individu harus rumuskan terlebih dahulu. Sifat-sifat genetik tersebut berkaitan erat dengan fungsi tujuan yang akan dicapai. Sifat genetik tersebut dalam teori evolusi sering juga di sebut kromosom dan gen. Proses dalam algoritma genetik terhadap kromosom dan gen tersebut adalah sebagai berikut: 
1. Natural Selection Proses seleksi alamiah (natural selection)

Dalam Algoritma Genetika (AG) ini digunakan metode seleksi dengan roda Roulette. Metode seleksi roda roulette ini merupakan metode yang populer digunakan karena metode ini masih memberikan kesempatan kepada individu dengan fitness yang rendah untuk dapat mengikuti proses optimasi.

2. Crossover

Tujuan dari proses penyilangan (crossover) adalah untuk memperoleh generasi baru yang memiliki nilai fitness lebih besar daripada generasi sebelumnya. Proses ini dilakukan dengan cara memilih 2 individu secara random sebagai kromosom induk (parent) kemudian dilakukan proses penyilangan sehingga memperoleh 2 kromosom anak (offspring). Pada penelitian ini digunakan rasio nilai probabilitas crossover yang direkomendasikan oleh Grefenstette, yaitu $p_{c o}=0.95$. Ada beberapa metode untuk melakukan proses crossover, namun untuk paper ini crossover dilakukan dengan menggunakan pemotongan tunggal pada kromosom induk.

3. Mutasi genetik

Tujuan dari proses mutasi adalah untuk mengurangi konvergen prematur pada Algoritma Genetika, karena mutasi memberikan karakter baru yang berbeda dengan aslinya. Pada penelitian ini digunakan nilai probabilitas mutasi yang direkomendasikan oleh Grefenstette, yaitu $p_{m}=0.01$.

\section{Fungsi Tujuan}

Fungsi tujuan dari proses optimasi pada paper ini adalah menentukan volume struktur yang optimum yang secara matematis dapat di tulis sebagai berikut:

a. Fungsi Tujuan untuk optimasi dengan modifikasi pada cross section,

$$
F(x)=V=\sum_{i=1}^{n} A_{i} \cdot L_{i}
$$

$A_{i}$ merupakan luas penampang dari masing-masing elemen dan $L_{i}$ merupakan panjang dari setiap elemen struktur.

b. Fungsi Tujuan untuk optimasi dengan modifikasi pada bentuk struktur dan cross section,

5. Fungsi Penalti

$$
F(x)=\sum_{i=1}^{n} P F_{i} \cdot A_{i} \cdot L_{i}
$$

Fungsi kendala untuk permasalahan optimasi pada paper ini dirumuskan sebagai berikut :

a. Fungsi penalti interior optimasi dengan modifikasi luasan penampang menggunakan

persamaan matematis berikut,

$$
\phi=F(x)+r_{1}\left(\sum_{i=1}^{n}\left\langle g_{i}(x)\right\rangle^{2}\right)
$$

b. Fungsi penalti interior optimasi dengan modifikasi bentuk dan luasan penampang menggunakan persamaan matematis berikut,

$$
\phi=F(x)+r_{1}\left(\sum_{i=1}^{n}\left\langle g_{i}(x) \cdot R M S\right\rangle^{2}\right)
$$

Dimana RMS adalah root mean square dari penampang struktur. Sementara, $\mathrm{r}_{1}$ merupakan faktor multiplikasi yang didapat secara trial and error. Pada optimasi luas penampang, $\mathrm{r}_{1}$ diterapkan dengan nilai tetap. Pada optimasi bentuk, faktor $r_{1}$ diaplikasikan bervariasi tergantung pada fase proses optimasi. Pada fase awal, proses optimasi diarahkan agar seluruh 
elemen yang didapatkan telah memenuhi fungsi kendala bentuk struktur. Pada fase selanjutnya, $\mathrm{r}_{1}$ di set untuk mengarahkan proses optimasi agar mampu mencari secara detail cross section penampang yang sesuai dengan fungsi kendala yang ingin dicapai.

III. ANALISA NUMERIK

Sebuah struktur rangka batang sederhana dengan 3 segmen seperti skema berikut:

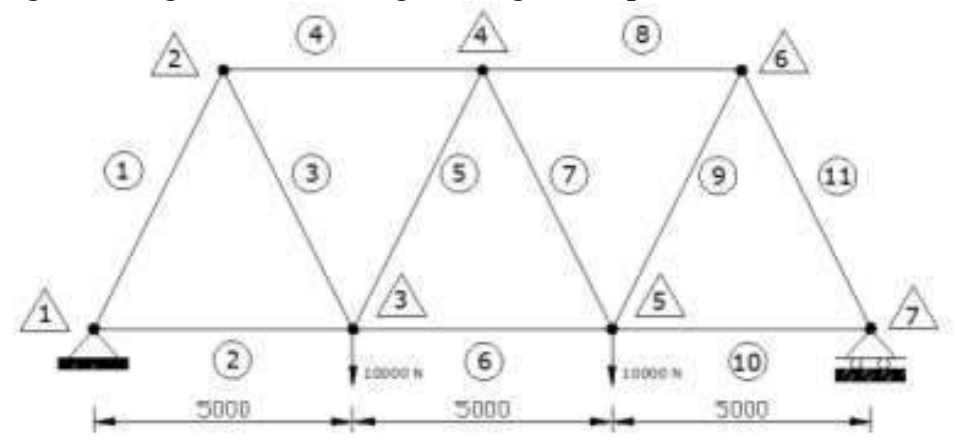

Gambar 2. Contoh objek penelitian struktur rangka batang

Adapun properties penampang struktur yang digunakan dalam analisa struktur tersebut meliputi:

a. Modulus Young (E) $200.000 \mathrm{MPa}$

b. Satuan dimensi adalah $\mathrm{mm}$

c. Area penampang di generate secara random oleh program

Struktur tersebut akan dianalisa menggunakan metode Algoritma Genetik dengan variable fungsi luas penampang (cross section) dan bentuk struktur. Analisa dilakukan dengan menggunakan source code yang di-generate pada MATLAB.

IV. HASIL

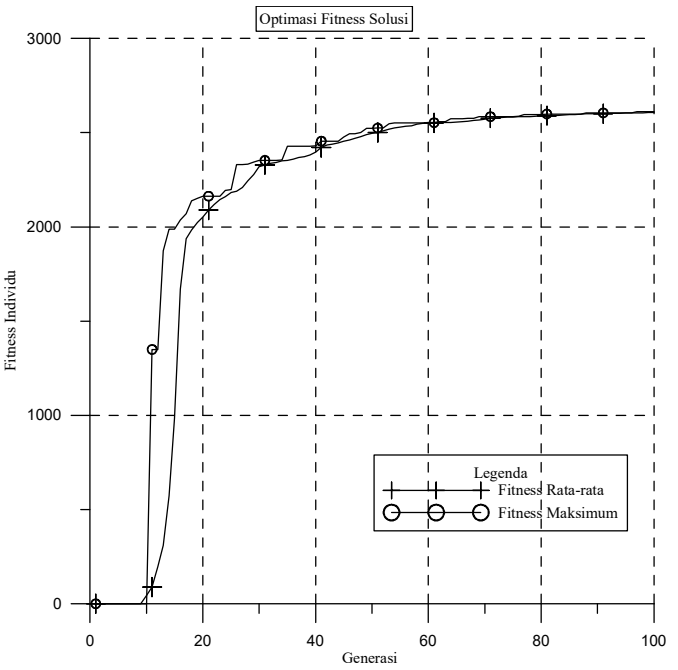

Gambar 3. Kurva Generasi vs Fitness Individu

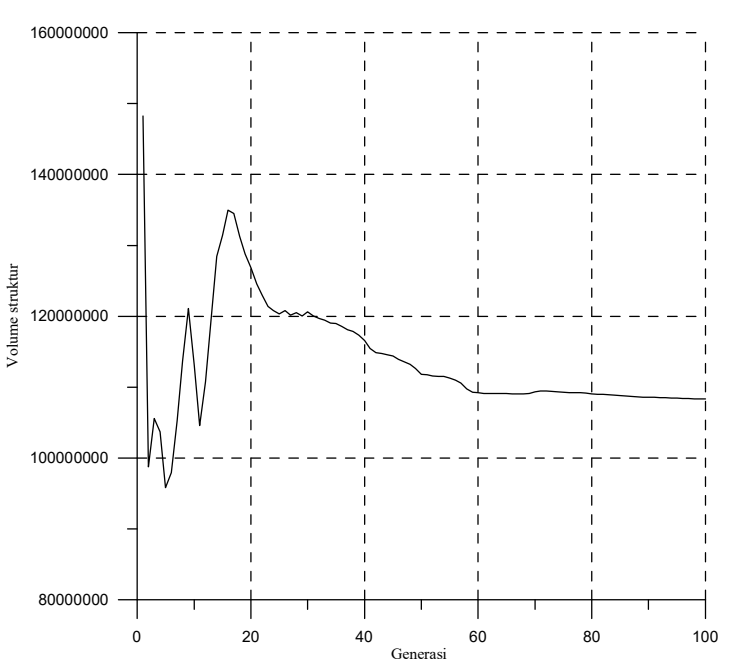

Gambar 4. Generasi vs Volume total 


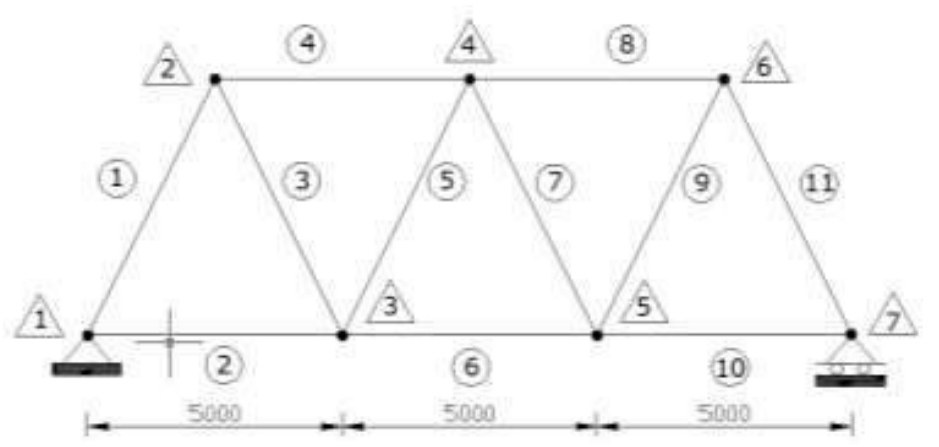

Gambar 5. Bentuk struktur hasil optimasi struktur dengan modifikasi cross section

Tabel 2. Kesimpulan solusi optimasi struktur dengan modifikasi cross section

\begin{tabular}{|c|c|c|c|c|c|c|c|c|c|c|c|}
\hline Elemen & 1 & 2 & 3 & 4 & 5 & 6 & 7 & 8 & 9 & 10 & 11 \\
\hline $\operatorname{Area}\left(\mathrm{mm}^{2}\right)$ & 80,60 & 62,7263 & 93,51 & 66,84 & 2,2 & 99,0 & 1,7 & 89,6 & 93,55 & 52,5257 & 78,72 \\
\hline PF & 0,004 & 7,71E-06 & 0,000 & 0,007 & 0 & 0,00 & 0 & 0,00 & 0,000 & $7,73 \mathrm{E}-05$ & 0,005 \\
\hline Syarat PF & 0.01 & 0.0001 & 0.001 & 0.01 & 0.0 & 0.00 & 0.0 & 0.01 & 0.001 & 0.0001 & 0.01 \\
\hline Keterangan & OK & OK & $\mathrm{OK}$ & $\mathrm{OK}$ & $\mathrm{OK}$ & $\mathrm{OK}$ & OK & $\mathrm{OK}$ & $\mathrm{OK}$ & OK & $\mathrm{OK}$ \\
\hline
\end{tabular}

Volume total dari solusi struktur paling optimum adalah $3812830.6 \mathrm{~mm}^{3}$.

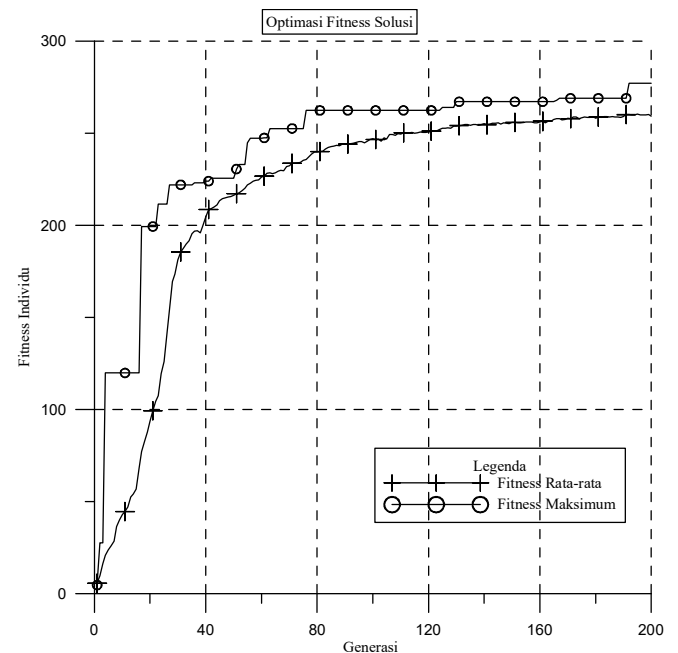

Gambar 6. Generasi vs Fitness Individu

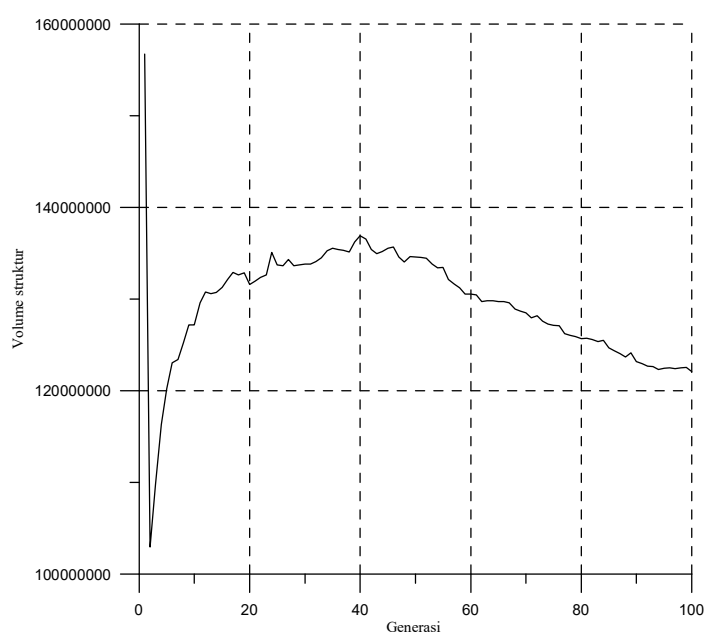

Gambar 7. Generasi vs Volume individu

Perkembangan fitness solusi untuk optimasi bentuk 


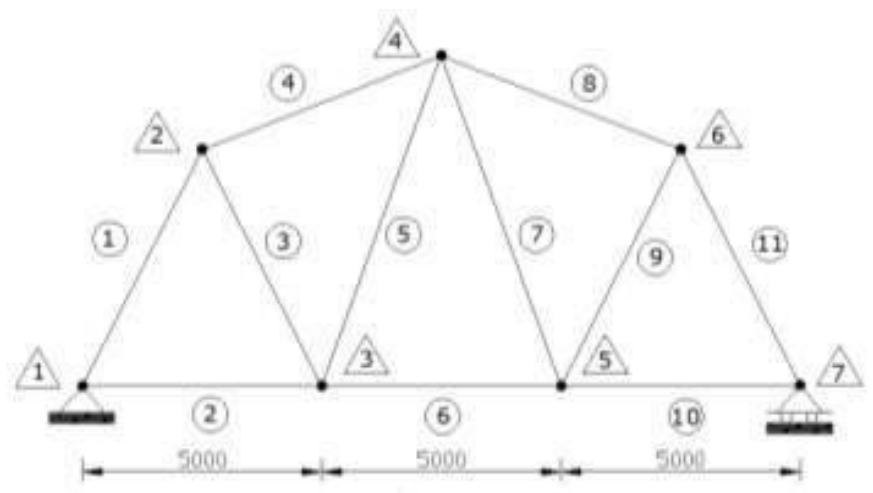

Gambar 8. Solusi bentuk struktur paling optimum dengan modifikasi bentuk struktur

Tabel 3. Kesimpulan solusi optimasi struktur dengan modifikasi bentuk dan cross section

\begin{tabular}{|c|c|c|c|c|c|c|c|c|c|c|c|}
\hline Elemen & 1 & 2 & 3 & 4 & 5 & 6 & 7 & 8 & 9 & 10 & 11 \\
\hline $\operatorname{Area}\left(\mathrm{mm}^{2}\right)$ & 79,5 & 70,2856 & 71,3 & 62,3 & 0,0 & 61,5 & 36,6466 & 63,7 & 63,7 & 58,1441 & 77,7 \\
\hline PF & 0,00 & 1,91E-06 & 0,00 & 0,00 & 0.0 & 0,00 & $8,29 \mathrm{E}-05$ & 0,00 & 0,00 & $2,57 \mathrm{E}-05$ & 0,00 \\
\hline Syarat PF & 0.01 & 0.0001 & 0.00 & 0.01 & 0.0 & 0.00 & 0.001 & 0.01 & 0.00 & 0.0001 & 0.01 \\
\hline Keterangan & $\mathrm{OK}$ & $\mathrm{OK}$ & OK & $\mathrm{OK}$ & $\mathrm{OK}$ & $\mathrm{OK}$ & $\mathrm{OK}$ & $\mathrm{OK}$ & $\mathrm{OK}$ & $\mathrm{OK}$ & $\mathrm{OK}$ \\
\hline
\end{tabular}

Nilai Ordinat dari nodal 2, 4 dan 6 yang memberikan hasil paling optimum adalah sebagai berikut:

Tabel 4. Nilai ordinat dari nodal yang menjadi variabel optimasi Y(i)

$\begin{array}{cc}\text { Deskripsi Node } & \text { Nilai } \\ \text { Y(2) } & 4923 \\ Y(4) & 6875 \\ Y(6) & 4929\end{array}$

Volume total dari solusi struktur paling optimum adalah $3510997.01 \mathrm{~mm}^{3}$.

\section{KESIMPULAN DAN SARAN}

Berdasarkan hasil analisa dapat ditarik kesimpulan sebagai berikut:

1. Hasil optimasi struktur dengan menggunakan modifikasi pada Cross Section memperlihatkan volume struktur yang menjadi solusi optimum dari permasalahan yang dipaparkan pada bagian III III aboveANALISA NUMERIK memperlihatkan volume struktur adalah $3812830.6 \mathrm{~mm}^{3}$. Struktur dengan volume tersebut dapat memenuhi performa struktur yang diinginkan dengan Probabilitas Kegagalan (PF) dari masing-masing elemen struktur berada pada level yang dibutuhkan.

2. Berdasarkan pengecekan performa fitness dari individu seluruh generasi, dapat dilihat bahwa fitness individu solusi memiliki total fitness terbaik yang berarti bahwa individu yang dijadikan solusi merupakan individu yang paling optimum untuk fungsi tujuan.

3. Optimasi bentuk pada objek studi rangka batang memperlihatkan hasil bahwa dengan melakukan modifikasi bentuk struktur yang dikombinasikan dengan modifikasi cross section, didapatkan hasil volume struktur optimum adalah $3510997.01 \mathrm{~mm}^{3}$. Probabilitas Kegagalan (PF) dari masingmasing elemen struktur berada pada level yang dibutuhkan.

4. Dari hasil analisa terlihat metode optimasi bentuk (shape optimization) bisa menghasilkan solusi yang lebih optimum dibandingkan optimasi penampang (cross section). Namun, shape 
optimization memiliki kelemahan pada waktu komputasi yang jauh lebih lama karena area solusi yang jauh lebih besar. Namun demikian, langkah-langkah untuk mengurangi iterasi dapat dilakukan dengan memodifikasi variabel-variabel genetik, salah satunya adalah nilai $r_{1}$.

Berdasarkan hasil penelitian pada paper ini, maka dapat di sarankan beberapa hal untuk pengembangan kedepan, antara lain:

1. Untuk pengembangan selanjutnya, model struktur yang akan di optimasi dapat dikembangkan kepada model-model struktur 3D.

2. Optimasi bentuk (shape optimization) membutuhkan proses komputasi yang sangat besar. Untuk mengurangi proses komputasi, penelitian pada paper ini menggunakan variable $r_{1}$ yang berubah berdasarkan fase optimasi. Dengan metode ini, proses konvergensi optimasi menjadi lebih cepat karena algoritma mampu menghasilkan struktur dengan fitness yang tinggi dalam proses yang lebih cepat. Namun demikian untuk model yang lebih kompleks, perlu di kembangkan metode optimasi dari variable $\mathrm{r}_{1}$, sehingga proses komputasi untuk model-model rumit tersebut dapat dilakukan lebih cepat.

\section{DAFTAR PUSTAKA}

Ang, A. H.-S. (1984). Probability Concept In Engineering Planning And Design Vol. II. John Wiley \& Sons, Inc.

Besari, M. a. (1994). Genetic Algorithms In Plane Truss Shape Optimization. 3rd Regional

Conference on Computer Applications In Civil Engineering. Kuala Lumpur.

(2010). Impact of Construction and the Building Environment. United Kingdom: Dixon, Willmot.

Kirsch, U. (1981). Optimum Structural Design. USA: McGraw-Hill.

Nasution, A. (2010). Metode Elemen Hingga. Bandung: Penerbit ITB. 